\title{
Early educators' practices and opinions in relation to pre-schoolers' dietary intake at pre-school: case Finland
}

\author{
Reetta Lehto ${ }^{1,2, *}$, Carola Ray ${ }^{1}$, Henna Vepsäläinen ${ }^{2}$, Liisa Korkalo ${ }^{2}$, Kaija Nissinen ${ }^{3}$, \\ Essi Skaffari ${ }^{1,2}$, Suvi Määttä ${ }^{1}$, Eva Roos ${ }^{1,2}$ and Maijaliisa Erkkola ${ }^{2}$ \\ ${ }^{1}$ Folkhälsan Research Center, Topeliuksenkatu 20, 00250 Helsinki, Finland: ${ }^{2}$ Department of Food and Environmental \\ Sciences, University of Helsinki, Helsinki, Finland: ${ }^{3}$ School of Food and Agriculture, Seinäjoki University of Applied \\ Sciences, Seinäjoki, Finland
}

Submitted 18 May 2018: Final revision received 12 December 2018: Accepted 3 January 2019: First published online 20 February 2019

\begin{abstract}
Objective: We aimed to examine associations between early educators' feeding practices and opinions and children's dietary intake at pre-school, in a context where uniform meals are served and pre-schools are highly regulated.

Design: Cross-sectional study. Food consumption data of the children consisted of two-day food records from pre-school kept by early educators. Early educators also reported their feeding practices and opinions on pre-school food. Serving style was observed.

Setting: Municipal pre-schools in Southern and Western Finland.

Participants: Pre-schoolers ( $n$ 586) aged 3-6 years and early educators ( $n$ 378).

Results: Early educators' positive opinion of the food served at pre-school and the opinion that sufficient vegetables were available for the children were positively associated with children's vegetable consumption. Early educators' role modelling and a positive opinion of the food were negatively associated with children's energy intake. Encouragement to eat fruit and vegetables was associated with higher fibre intake. Intake of added sugar was low ( $4.4 \%$ of energy).

Conclusions: Some of the feeding practices and opinions of early educators were related to healthier dietary intake (higher vegetable consumption and fibre intake) among the children. However, in some respects, the results contradicted previous findings. Overall, early educators' feeding practices and opinions contribute to children's dietary intake and should be taken into account when promoting healthy food intake among pre-school children.
\end{abstract}

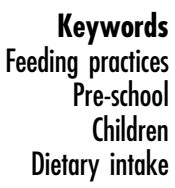

In many Western countries, including Finland, children under school age are known to eat too little fruit and vegetables $^{(1)}$ and too much sugar ${ }^{(2,3)}$ compared with recommendations ${ }^{(4)}$. Since the prevalence of childhood overweight/obesity has risen dramatically during recent decades $^{(5)}$, special attention should be paid to children's dietary intake. In addition, eating habits and food preferences, along with other health behaviours, are formed early in life and they tend to track into adulthood ${ }^{(6,7)}$. Thus, early childhood is a critical period for subsequent health behaviours and health.

Parental modelling, feeding style and feeding practices have all been found to affect children's food intake ${ }^{(8-10)}$. The role of other adults may also be important, since, according to social cognitive theory, eating behaviour (as well as other behaviours) is learned in early childhood by observing and imitating ${ }^{(11)}$. As most young children in
Western countries attend formal childcare ${ }^{(12)}$, childcare settings and early educators may also play an important role in shaping children's dietary intake ${ }^{(13)}$. Indeed, early educators acknowledge that they serve as role models for food eating behaviour ${ }^{(14)}$. This is reflected in the new food recommendations for early childhood education in Finland, which also stress that the mealtime is a learning opportunity where each early educator sets an example and serves as a role model by discussing various topics and interacting and eating with the children ${ }^{(15)}$.

In Finland, pre-schools provide children with three meals per day: breakfast, which is usually porridge and/or bread; a warm lunch, milk and crisp bread; and an afternoon snack. In the present paper, we use 'pre-school' to refer to centre-based early childhood education and care, which in Finland is voluntary until the age of 6 years and compulsory for one year before school begins at the age of 
7 years. Very few studies have investigated the nutritional quality of the food served in pre-school in Finland, but pre-school catering services should follow meal recommendations ${ }^{(15,16)}$. The meals are mainly cooked, and the menus planned, at the catering services from which the municipalities buy the pre-school food, and thus the food is mostly the same in every pre-school within a municipality. Children should receive two-thirds of their energy and nutrient requirements during the pre-school day if the child attends a full day in pre-school (thereby eating three meals in pre-school) ${ }^{(15)}$. For 3-6-year-olds, this amount of energy corresponds to approximately $3600-4400 \mathrm{~kJ}$. Although the quality of pre-school food has not been directly studied, some indication of the healthiness of the food exists. For example, studies comparing the nutrient intakes of children of pre-school age cared for at home with those children cared for in pre-school have found that the latter have a healthier diet ${ }^{(17,18)}$.

Only a limited number of studies have examined feeding practices, such as staff role modelling of healthy eating, encouragement to eat fruit and vegetables, and use of food as a reward, in relation to children's dietary intake in childcare. Moreover, in Europe, such studies have been conducted only in the Netherlands ${ }^{(19,20)}$. The results of these studies have been mixed $^{(19,21-23)}$, due perhaps in part to differences in mealtime arrangements, in the foods served in childcare and in the factors studied. Furthermore, early educators' attitudes towards and opinions on childcare food have not been studied, although they might affect the behaviour of these educators during mealtimes. Therefore, it is important to examine these associations in new contexts and in pre-school settings where predominantly healthy food is served, such as Finnish preschools. Thus, the aim of the present study was to examine the practices and opinions of early educators concerning pre-school food in relation to the dietary intake of 3-6-year-old children in pre-school in Finland.

\section{Methods}

The present study is part of the DAGIS study and its crosssectional survey in pre-schools in 2015-2016 ${ }^{(24,25)}$. The aim of DAGIS is to examine 3-6-year-old children's health behaviour and stress regulation and their determinants, with special emphasis on socio-economic differences. Preschools in eight municipalities in Southern and Western Finland were invited to participate in the study. The eligibility criteria for the pre-schools were that: (i) the pre-school was Finnish- or Swedish-speaking (official languages in Finland); (ii) the pre-school was public (municipal) or the municipality purchased early education services from the pre-school; (iii) the pre-school functioned during the daytime only (no $24 \mathrm{~h}$ pre-schools); (iv) the pre-school charged income-dependent fees (all municipal pre-schools charge income-dependent fees); and (v) the pre-school had at least one group of approximately 3-6-year-old children. One hundred and sixty-nine pre-schools were invited, of which sixteen were excluded based on the eligibility criteria. Of the remaining 153 pre-schools, eighty-six pre-schools consented to participate (56\%). Nevertheless, in twenty of those preschools, the participation rate of families remained too low (below $30 \%$ in every child group), and thus the study was conducted in sixty-six pre-schools. Written informed consent was received from the pre-school managers and parents of the participating children. The early educators, however, did not sign a consent form; the pre-school managers decided if the pre-school would participate and completion of the questionnaires remained voluntary for the early educators. The consent rate for children was $27 \%$ (983 out of 3592 invited), which left a total of 892 consenting children in pre-schools where the study was conducted. We received at least some data from 864 of these children, who ultimately formed the participants of the study ( $24 \%$ of all invited).

\section{Early educators' feeding practices and opinions}

In Finland, pre-school groups include teachers, specialised teachers, nursery nurses and assistants, all of whom we collectively term 'early educators' in the present paper. Each pre-school group usually consists of three early educators and a little over twenty children. All early educators in the pre-school groups were asked to complete a questionnaire assessing their feeding practices and opinion of the pre-school food. A total of 378 early educators completed the questionnaire (response rate $78 \%$ ).

A description of the feeding practice variables used in the study can be found in Table 1 . Some of the feedingpractice items were self-developed based on focus group interviews with pre-school personnel ${ }^{(10)}$, while some were taken from the Nutrition and Physical Activity SelfAssessment for Child Care (NAP SACC) self-assessment tool $^{(26)}$. The self-developed questions have not been validated, but the items from the NAP SACC questionnaire have been validated against observation ${ }^{(26)}$. The validated and non-validated questions are marked in Table 1. A feasibility pilot study (R Kaukonen, S Hampf and C Ray, unpublished results) was conducted prior to the actual study, but it yielded no changes to the food practice items. Role modelling was determined from the questions 'How many times per week do you eat the same lunch as the children?' (open-ended question) and 'Where do you usually eat your lunch on weekdays?' (answer options: 'together with the children at the same table', 'in the same room with the children but at a different table', 'in preschool away from the children', 'somewhere else' and 'I don't eat lunch'). The frequency of eating the same lunch as the children formed the role modelling variable for those early educators who reported usually eating at the same table with the children. For others, this variable was 
Table 1 Description of feeding practices and early educators' opinion of the food

\begin{tabular}{|c|c|c|c|c|}
\hline $\begin{array}{l}\text { Feeding practice or opinion } \\
\text { of the food }\end{array}$ & Question(s) & Scale & Mean or $\%$ & SD \\
\hline \multicolumn{5}{|l|}{ Early educator level } \\
\hline Role modelling (\%) & $\begin{array}{l}\text { Where do you usually eat your lunch on } \\
\text { weekdays }{ }^{\star} \text { ? }\end{array}$ & $\begin{array}{l}\text { (i) 'Together with children, at the same } \\
\text { table' v. other options: (ii) 'In the } \\
\text { same room with children but at a } \\
\text { different table'; (iii) 'In pre-school } \\
\text { away from the children'; (iv) } \\
\text { 'Somewhere else'; (v) 'I don't eat } \\
\text { lunch' }\end{array}$ & 82 & - \\
\hline & $\begin{array}{l}\text { How many times per week do you eat the } \\
\text { same food as the children at lunch? }\end{array}$ & & $3 \cdot 1 \ddagger$ & $2 \cdot 4$ \\
\hline $\begin{array}{l}\text { Positive opinion of the } \\
\text { food }\end{array}$ & $\begin{array}{l}\text { (i) 'The food served in pre-school is healthy'*; } \\
\text { (ii) 'The food served in pre-school is } \\
\text { versatile**; (iii) 'The food served in pre- } \\
\text { school is tasty'*; (iv) 'The food served in } \\
\text { pre-school is appetising'; (v) 'The food } \\
\text { served in pre-school is suitable for } \\
\text { children'* }\end{array}$ & $\begin{array}{l}1=\text { 'totally disagree' to } 5=\text { 'totally } \\
\text { agree' }\end{array}$ & $3.3 \S$ & 0.9 \\
\hline $\begin{array}{l}\text { Encouragement to eat } \\
\text { fruit and vegetables }\end{array}$ & $\begin{array}{l}\text { (i) 'How often do you praise the children } \\
\text { when they try new or unpopular fruit, } \\
\text { berries or vegetables?'†; (ii) 'How often do } \\
\text { you urge the children repeatedly to taste } \\
\text { new or unpopular fruit, berries or } \\
\text { vegetables?'*; (iii) 'How often do you } \\
\text { encourage the children to eat fruit, berries } \\
\text { or vegetables?’* }\end{array}$ & $1=$ 'never' to $5=$ 'always' & $4.6 \S$ & 0.5 \\
\hline Using food as a reward & $\begin{array}{l}\text { 'How often do you reward the children with } \\
\text { other food for eating vegetables?' } \dagger\end{array}$ & $1=$ 'never' to $5=$ 'always' & 1.9 & 1.0 \\
\hline $\begin{array}{l}\text { Opinion on the adequacy } \\
\text { of vegetables } \\
\text { Pre-school group level (\%) }\end{array}$ & $\begin{array}{l}\text { 'There are enough vegetables served in the } \\
\text { pre-school'* }\end{array}$ & $\begin{array}{l}1=\text { 'totally disagree' to } 5=\text { 'totally } \\
\text { agree' }\end{array}$ & $3 \cdot 3$ & $1 \cdot 3$ \\
\hline $\begin{array}{l}\text { Vegetable serving style } \\
\text { (observation) }\end{array}$ & $\begin{array}{l}\text { How are the vegetables served in the first } \\
\text { serving? } \dagger\end{array}$ & $\begin{array}{l}\text { Ready-made portions } \\
\text { Staff chooses and serves } \\
\text { Children choose and staff serves } \\
\text { Children serve themselves }\end{array}$ & $\begin{array}{l}10 \\
21 \\
38 \\
30\end{array}$ & $\begin{array}{l}- \\
- \\
-\end{array}$ \\
\hline $\begin{array}{l}\text { Main course serving } \\
\text { style (observation) }\end{array}$ & $\begin{array}{l}\text { How is the main course served in the first } \\
\text { serving?† }\end{array}$ & $\begin{array}{l}\text { Ready-made portions } \\
\text { Staff chooses and serves } \\
\text { Children choose and staff serves } \\
\text { Children serve themselves }\end{array}$ & $\begin{array}{r}9 \\
21 \\
41 \\
28\end{array}$ & $\begin{array}{l}- \\
- \\
- \\
-\end{array}$ \\
\hline
\end{tabular}

*Self-developed, not validated.

†From the Nutrition and Physical Activity Self-Assessment for Child Care (NAP SACC) questionnaire, validated ${ }^{(26)}$. ¥Mean of those early educators who eat at the same table together with the children. §Mean of the sum variable.

set to 0. Encouragement to eat fruit and vegetables was a sum variable formed from the questions 'How often do you praise the children when they try new or unpopular fruit, berries or vegetables?', 'How often do you urge the children repeatedly to taste new or unpopular fruit, berries or vegetables?' and 'How often do you encourage the children to eat fruit, berries or vegetables?' The answer options for these questions were 'never', 'rarely', 'sometimes', 'often' and 'always'. Another sum variable was formed to capture the early educators' opinion of the food served in pre-school. The statements were 'The food served in pre-school is healthy', '... versatile', '... tasty', '... appetising' and '... suitable for children'. The answers were given on a 5-point Likert scale from 'strongly disagree' to 'strongly agree'. The early educators also reported on whether they thought enough vegetables were served in pre-school (5-point Likert scale) and how often they rewarded children with other food for eating vegetables (with the response options 'never', 'rarely', 'sometimes', 'often' and 'always'). Finally, the early educators reported whether they thought that there was (i) too little, (ii) the right amount or (iii) too much sugar in the food served in pre-school.

A trained researcher/research assistant observed the lunchtime serving style of vegetables (mainly consisting of salad) and the main course. The observation was based on the Environment and Policy Assessment and Observation tool developed by Ward et al. ${ }^{(27)}$. The observer completed a questionnaire on different lunchtime practices while observing the meal situation. The answer options for serving style are found in Table 1 . The answers were divided into 'the children serve themselves' and 'other'. The lunch situations of 133 (84\%) out of 159 pre-school groups were observed.

\section{Food intake data}

The children's food intake during pre-school hours was assessed using two-day pre-coded food records 
completed by the early educators. The food record was pre-coded to aid completion, with breakfast, lunch and snack each having predefined pages. In addition, the food groups in each meal, such as main course, side dishes (potatoes, pasta, rice) and salad/other vegetables at lunch, each had predetermined rows. The early educators entered the foods and drinks the child had consumed and their amounts. Furthermore, if they occurred, other foods and other eating occasions were also entered. The early educators estimated portion sizes either in household measures or by using the validated Children's Food Picture Book, which was developed in the DAGIS project ${ }^{(28)}$. The book contains pictures of foods commonly eaten by Finnish children in different portion sizes. Recipes for the foods served and information on the foodstuffs used were received in full from the municipal pre-school catering service in five out of eight municipalities. In addition, the food service in one municipality provided incomplete information (not all the recipes), while food services in two municipalities gave no information at all. In cases where the recipe was lacking, recipes from other catering services were used, whereas the national food composition database was used in the case of missing foodstuff information.

In addition to the pre-school food record, parents of the participating children also kept a food record for their child on two weekdays and one weekend day. The two weekdays were the same days during which the food record was also kept at pre-school. The days were assigned by the research group. The food record included an instruction page and one filled page as an example. The parents were instructed to report all foods and beverages the child consumed outside pre-school hours. The parents were also provided with the Children's Food Picture Book ${ }^{(28)}$ to assist in portion size estimation. Alternatively, portion sizes were to be estimated by weighing, by household measures or from package labels. All ingredients of composite dishes were to be reported and product names given for packed food products. Research assistants checked the returned food records and made follow-up telephone calls if important information was missing.

The data from the food records were entered into the nutritional calculation software program AivoDiet version 2.2.0.0 (Aivo Finland Oy, Turku, Finland) for computation of the food consumption and nutrient intakes of the children. AivoDiet uses the Finnish national food composition database Fineli, which is maintained by the Finnish National Institute for Health and Welfare ${ }^{(29)}$.

In the analyses, we used the data from those children who had eaten all three meals (breakfast, lunch and afternoon snack) on at least one pre-school day. If the child had eaten a meal (e.g. breakfast) on two days, the mean dietary intake of these meals was calculated and used in the analyses.

The dietary intake variables analysed in the present study were the intake of raw and cooked vegetables $(\mathrm{g} / \mathrm{d}$; not including potatoes or vegetables in main dishes), the percentage of daily energy intake from preschool food, fibre density ( $\mathrm{g} / \mathrm{MJ}$ ) and added sugar (as a percentage of energy intake (E\%)). Vegetables, added sugar and fibre were chosen because children often fail to meet the recommendations in these dietary factors. In Finland, the child nutrition recommendation for fruit and vegetables is a minimum of five handfuls (about $250 \mathrm{~g}$ ) daily. The recommendation for fibre density is $3 \mathrm{~g} / \mathrm{MJ}$ and for added sugar $\leq 10 \mathrm{E} \%{ }^{(16)}$. The proportion of the children's daily energy intake obtained from pre-school food was chosen in order to compare the results with the recommendation, which states that pre-school food should cover, on average, two-thirds of the child's energy and nutrient needs. We calculated the total daily energy intake of the children on pre-school days as the sum of energy intake during out-of-pre-school hours and preschool hours.

The estimate for intake of added sugar was calculated by assigning each food item to a food group. Each food group containing significant amounts of sugar ( $n$ 41) was then given an average formula that represents the foods in that group, for the calculation of added sugar. The sucrose and total sugar content of each food was available in the composition database. The formula was an estimate of the proportion of added sugar of total sugar in that food group. To estimate the relative amounts of naturally occurring and added sugar in a certain food, we used information from package labels, the national food composition database ${ }^{(29)}$ and commonly used recipes about the proportion of ingredients including natural sugars (e.g. fruits, berries) in this food. For instance, to calculate added sugar in 'sugar-sweetened jams and marmalade', the total sugar value for each food in that group was multiplied by the estimated proportion. If the food did not contain significant amounts of natural sugars all sugar was treated as added sugar. For instance, products in the group 'salad dressings' were considered to contain negligible amounts of natural sugars and thus the formula stated that added sugar equals total sugar. Furthermore, if the food was considered to include only negligible amounts of natural sucrose and the sweetener was sucrose, the added sugar content was estimated to equal the sucrose value of that food. For instance, for products in the group 'pancakes', the formula stated that added sugar equals total sucrose. In order to transform the vegetable consumption variable into a normally distributed variable, square-root transformation was used.

\section{Confounders}

The children's age (in years), gender and municipality were used as confounders. Municipality was controlled for since municipalities are responsible for the catering in municipal pre-schools and they may affect feeding practices through their regulations. In addition, the intake of 
energy was controlled for in the vegetable intake analyses and vice versa.

\section{Statistical analyses}

The associations between early educators' feeding practices and opinions and children's dietary intake were analysed with linear regression models. The opinion that pre-school food contained too much sugar was analysed only in relation to added sugar intake. Two models were used: (i) a crude model with no adjustments and (ii) a model adjusted for the child's gender, age and municipality (and energy intake in analyses on vegetable intake, and vegetable consumption in analyses on energy intake). Since there were several early educators present in each pre-school group, the early educators' practices and opinions were aggregated within the group, and the mean values of each practice and opinion were used as independent variables for each child in the group. For example, when analysing the association between early educators' positive opinion of the food and children's vegetable intake, the independent variable was the mean value of that opinion for the early educators in each preschool group. To take account of the nested design of the sample, confidence intervals were adjusted for clustering on the pre-school level ${ }^{(30)}$. The statistical software packages IBM SPSS Statistics version 23.0 and Mplus version $7.4^{(30)}$ were used to conduct the statistical analyses.

\section{Results}

The characteristics of the children and early educators and the children's dietary intake in pre-school are found in Table 2. In total, 586 children had eaten all three meals in pre-school on at least one day and thus form the data in the present study. They represent $68 \%$ of the 864 study participants and $72 \%$ of those 822 children from whom we received some food-record data from pre-school. These 586 children did not differ from the 822 children by age, gender, BMI or familial education level (data not shown). On average, they consumed $38 \mathrm{~g}$ of vegetables and received $3229 \mathrm{~kJ}$ of energy and $9.4 \mathrm{~g}$ of fibre during a preschool day (Table 2). Fifty-five per cent of energy intake on a pre-school day was consumed in pre-school. Their average intake of added sugar was $4.4 \mathrm{E} \%$.

Associations between the early educators' feeding practices and opinions and the children's dietary intake are found in Table 3. Early educators' positive opinion of the food served in pre-school were positively associated with the children's vegetable consumption. In addition, agreement on the adequacy of vegetables served to the children was positively associated with the children's vegetable consumption. By contrast, staff role modelling and a positive opinion of the food were negatively associated with the children's energy intake. In turn, encouragement to eat fruit and vegetables was positively associated with the children's fibre intake. Finally, early educators' opinion that pre-school food contained excessive sugar was associated with higher added sugar intake in the crude model, but none of the practices or opinions were associated with added sugar intake in the adjusted model.

\section{Discussion}

In the present study, we tested for cross-sectional associations between early educators' feeding practices and opinions of pre-school food and children's dietary intake during the pre-school day. The results showed that some practices and opinions were indeed associated with children's dietary intake. For example, early educators' positive opinion of the food served in pre-school and the opinion that sufficient vegetables were available for the children were positively associated with children's vegetable consumption. In turn, staff role modelling (i.e. eating the same food at the same table with the children and a positive opinion of the food) were negatively associated with children's energy intake. Furthermore, encouragement to eat fruit and vegetables was associated with higher fibre intake. However, no associations with children's added sugar intake were found.

The results of previous studies on the associations between the feeding practices of pre-school staff and children's food intake have been mixed, partly because of variations in the practices and outcomes studied ${ }^{(19-23)}$. Two studies have found that staff role modelling (eating the same food as the children in their presence) is associated with higher sugar intake among the children ${ }^{(20,23)}$. As Ward et al. ${ }^{(23)}$ suggest, the reason for this association may lie in the foods served in pre-school: staff role modelling encourages children to eat more and if the foods served are high in sugar, this results in increased sugar intake. In turn, Kharofa et al. ${ }^{(22)}$ found that role modelling associates with higher energy and vegetable intake (sugar intake was not studied), which supports the theory that staff role modelling increases children's food consumption. Nevertheless, Andreyeva et al. ${ }^{(21)}$ found no associations between staff role modelling and children's dietary intake. In contrast to the above, our study found that staff role modelling was associated with lower energy intake. This result also persisted after controlling for vegetable intake, and thus it cannot be explained by higher vegetable consumption. The reason for this is unknown. A positive opinion of the food among staff correlated positively with role modelling (data not shown), and thus it would be improbable that early educators who ate the same lunch with the children disliked the food and somehow discouraged the children from eating it. On the contrary, one could speculate that early educators are more likely to eat and like the food in pre-schools where 
Table 2 Characteristics of the early educators and children and children's dietary intake in pre-school; DAGIS study and its cross-sectional survey conducted in pre-schools in eight municipalities in Southern and Western Finland, 2015-2016

\begin{tabular}{|c|c|c|}
\hline & Mean or \% & SD \\
\hline \multicolumn{3}{|l|}{ Child-level characteristics ( $n$ 586) } \\
\hline Age (years) & 4.7 & 0.9 \\
\hline $\mathrm{BMl}\left(\mathrm{kg} / \mathrm{m}^{2}\right)$ & $15 \cdot 9$ & 1.4 \\
\hline Gender (\% girls) & 47 & - \\
\hline \multicolumn{3}{|l|}{ Highest education level in the family* (\%) } \\
\hline Low† & 20 & - \\
\hline Medium $\ddagger$ & 43 & - \\
\hline High§ & 37 & - \\
\hline \multicolumn{3}{|c|}{ Children's dietary intake in pre-school (breakfast, lunch and afternoon snack) ( $n$ 586) } \\
\hline Energy $(\mathrm{kJ})$ & 3229 & 910 \\
\hline Energy (kcal) & 771 & 217 \\
\hline Percentage of daily energy intake in pre-school & $55 \cdot 0$ & $10 \cdot 5$ \\
\hline Fibre $(g)$ & $9 \cdot 4$ & $3 \cdot 1$ \\
\hline Fibre density (g/MJ) & 3.0 & 0.8 \\
\hline Vegetables $(\mathrm{g})$, raw and cooked & 38.5 & $28 \cdot 3$ \\
\hline Added sugar (g) & $9 \cdot 8$ & $12 \cdot 8$ \\
\hline Added sugar (E\%) & 4.4 & 3.5 \\
\hline \multicolumn{3}{|l|}{ Early educators' characteristics ( $n$ 378) } \\
\hline Gender (\% women) & 97 & - \\
\hline Age (years) & $42 \cdot 0$ & $11 \cdot 6$ \\
\hline \multicolumn{3}{|l|}{ Education level in early childhood education (\%) } \\
\hline None & 5 & - \\
\hline Vocational qualification & 51 & - \\
\hline Bachelor of social services/social pedagogue & 21 & - \\
\hline Kindergarten teacher or higher & 22 & - \\
\hline
\end{tabular}

$\mathrm{E} \%$, percentage of energy intake.

${ }^{*}$ Highest education between mother and father.

†Upper-secondary school, vocational school or lower.

$\ddagger$ College-level education or bachelor's degree.

§Master's degree or higher.

the food is less energy-dense. Nevertheless, other factors such as the haste or restlessness of the meal situation might prevent early educators from providing positive role modelling examples to the children.

In the present study, we also examined the early educators' opinion of the pre-school food, the rationale being that if they thought positively about the food, it would show in the way they encouraged the children to eat it. On the other hand, their opinion of the food may be an indicator of its quality and also reflect the children's attitude towards it. We are unaware of other studies on staff opinion of pre-school food and children's dietary intake. A positive opinion of the food was associated with higher vegetable consumption and lower energy intake. The association with vegetable intake can be due to both staff enthusiasm and the quality of, or children's attitude towards, the food. By contrast, the association between early educators' positive opinion of the food and lower energy intake is more challenging to interpret. However, it could relate to the energy density of the food: staff may prefer food with a lower energy density. This is supported by additional analyses, where we found that early educators' positive opinion of the food was not (significantly) associated with the amount of food the children had eaten. Moreover, although we had controlled for the children's vegetable consumption, the vegetable variable did not include vegetables in main courses, which probably affect the food's energy density. On the other hand, some studies show that the taste preferences of children and adults differ, at least concerning salty and sweet tastes ${ }^{(31)}$. Thus, the food preferred by staff may not be to the liking of children, who consequently eat less. Staff opinion on the adequacy of vegetables served in pre-school was associated with the consumption of vegetables among the children, which is a logical result if this opinion reflects the true amount and, partly, the quality of vegetables served in pre-school.

A family serving style (children serve themselves) is recommended practice in pre-schools ${ }^{(15,32,33)}$, although studies on its associations with children's dietary intake have yielded mixed results. Thus, it has been associated with either higher vegetable consumption ${ }^{(22)}$ or higher saturated fat and fibre intake ${ }^{(19)}$ or found to have no associations whatsoever ${ }^{(20,21,23)}$. In our study, a family style for serving vegetables was associated with higher vegetable consumption in the crude model, but with adjustments the association disappeared.

In the present study, no associations with added sugar intake were found. Overall, added sugar intake was very low. Other studies from North America and the Netherlands have reported that sugar-rich foods and drinks are often consumed in pre-school ${ }^{(20,23,34,35)}$. For example, 
Table 3 Linear regression estimates, and their $95 \% \mathrm{Cl}$, for the associations between early educators' practices and opinions and children's dietary intake in pre-school; DAGIS study and its cross-sectional survey conducted in pre-schools in eight municipalities in Southern and Western Finland, 2015-2016

\begin{tabular}{|c|c|c|c|c|c|c|}
\hline & \multicolumn{3}{|c|}{ Model 1} & \multicolumn{3}{|c|}{ Model 2} \\
\hline & $B$ & $95 \% \mathrm{Cl}$ & $P$ & $B$ & $95 \% \mathrm{Cl}$ & $P$ \\
\hline \multicolumn{7}{|l|}{ Vegetables (g) } \\
\hline Children self-serve & 0.79 & $0.08,1.51$ & 0.02 & 0.30 & $-0.55,1.15$ & 0.49 \\
\hline Staff role modelling & 0.09 & $-0.08,0.25$ & 0.32 & 0.09 & $-0.07,0.25$ & 0.27 \\
\hline Positive staff opinion of the food & 0.57 & $0.13,1.02$ & 0.01 & 0.54 & $0.13,0.95$ & 0.01 \\
\hline Staff opinion on adequacy of vegetables & 0.41 & $0.12,0.69$ & 0.01 & 0.32 & $0.03,0.60$ & 0.03 \\
\hline Encouragement to eat FV & 0.22 & $-0.57,1.00$ & 0.59 & 0.42 & $-0.30,1.14$ & 0.25 \\
\hline Using food as reward for eating vegetables & -0.24 & $-0.54,0.06$ & 0.12 & $-0 \cdot 10$ & $-0.38,0.18$ & 0.47 \\
\hline \multicolumn{7}{|l|}{ Percentage of daily energy intake in pre-school } \\
\hline Children self-serve & 0.78 & $-2 \cdot 20,3 \cdot 76$ & 0.61 & $-0 \cdot 15$ & $-3.94,3.63$ & 0.94 \\
\hline Staff role modelling & -0.77 & $-1.73,0.17$ & 0.01 & -0.81 & $-1.60,0.02$ & 0.046 \\
\hline Positive staff opinion of the food & -1.85 & $-3.92,0.23$ & 0.08 & -2.88 & $-4.86,0.89$ & 0.004 \\
\hline Staff opinion on adequacy of vegetables & -0.64 & $-1.73,0.45$ & 0.25 & -0.86 & $-2 \cdot 15,0.44$ & 0.20 \\
\hline Encouragement to eat FV & 0.64 & $-2 \cdot 94,4 \cdot 22$ & 0.73 & $1 \cdot 26$ & $-2.96,5.49$ & 0.56 \\
\hline Using food as reward for eating vegetables & -0.56 & $-2 \cdot 60,1.48$ & 0.59 & 0.42 & $-1 \cdot 72,2 \cdot 55$ & 0.70 \\
\hline \multicolumn{7}{|l|}{ Fibre density } \\
\hline Children self-serve & -0.02 & $-0.24,0.20$ & 0.74 & -0.11 & $-0.34,0.11$ & 0.33 \\
\hline Staff role modelling & 0.01 & $-0.03,0.06$ & 0.54 & -0.02 & $-0.07,0.03$ & 0.47 \\
\hline Positive staff opinion of the food & 0.06 & $-0.09,0.20$ & 0.44 & -0.01 & $-0.13,0.10$ & 0.84 \\
\hline Staff opinion on adequacy of vegetables & 0.01 & $-0.08,0.10$ & 0.87 & -0.03 & $-0.11,0.05$ & 0.52 \\
\hline Encouragement to eat FV & 0.30 & $0.06,0.53$ & 0.02 & 0.29 & $0.05,0.53$ & 0.02 \\
\hline Using food as reward for eating vegetables & $0 \cdot 11$ & $-0.01,0.23$ & 0.08 & 0.12 & $-0.01,0.25$ & 0.07 \\
\hline \multicolumn{7}{|l|}{ Added sugar $(\mathrm{E} \%)$} \\
\hline Children self-serve & -0.03 & $-1 \cdot 15,1 \cdot 10$ & 0.96 & -0.46 & $-1.45,0.53$ & 0.36 \\
\hline Staff role modelling & -0.16 & $-0.38,0.05$ & 0.14 & $-0 \cdot 10$ & $-0.30,0.10$ & 0.31 \\
\hline Positive staff opinion of the food & -0.36 & $-0.85,0.14$ & 0.16 & -0.07 & $-0.56,0.40$ & 0.77 \\
\hline Using food as reward & -0.15 & $-0.85,0.55$ & 0.67 & -0.05 & $-0.58,0.47$ & 0.84 \\
\hline $\begin{array}{l}\text { Staff opinion that there is too much sugar in the food served } \\
\text { in pre-school }\end{array}$ & $1 \cdot 76$ & $0.22,3.30$ & 0.03 & $1 \cdot 31$ & $-0 \cdot 21,2 \cdot 83$ & 0.09 \\
\hline
\end{tabular}

FV, fruit and vegetables; E\%, percentage of energy intake.

Model 1: no adjustments.

Model 2: adjusted for child's age, gender and municipality (and energy intake when the outcome was vegetable consumption, and vegetable intake when the outcome was energy intake).

Significant results indicated in bold $(P<0.05)$.

according to Ward et al. ${ }^{(23)}$ and Andreyeva et al. ${ }^{(21)}$, the intake of (total) sugar at lunch was 13-14 g among Canadian and US pre-schoolers, whereas in our study it was $2.5 \mathrm{~g}$ (data not shown). Since the intake of (added) sugar is so low in Finnish pre-schools, it is unsurprising that no associations with added sugar intake were found.

Encouragement to eat fruit and vegetables was positively associated with fibre intake, but not with vegetable consumption. In Finnish pre-schools, high-fibre rye crackers are often served at lunch and other meals. Although crackers are a normal part of the meal, they are sometimes withheld from children until they have eaten other parts of the meal, although guidelines warn against using bread as a reward in this way ${ }^{(15)}$. Encouragement to eat fruit and vegetables might take the form of rewarding with a rye cracker, which could then lead to higher fibre intake. In other observational studies, verbal encouragement to eat fruit and vegetables (or new/less-favoured foods) has generally yielded no associations with dietary intake ${ }^{(19,20,22,23)}$.

Associations with the consumption of fruit were not examined in the present study, since the intake of fruit was low and the percentage of non-consumers was high (approximately 40\%; data not shown). This is probably due to the low availability of fruit in Finnish pre-schools: $48 \%$ of early educators thought that the amount of fruit and berries served to the children in pre-school was too low (data not shown).

One strength of the present study is that it examined early educators' feeding practices and children's dietary intake in the context of highly regulated municipal preschools (attended by the majority of pre-schoolers), which, although not directly studied, are thought to serve healthy and uniform meals to all children ${ }^{(17,18)}$. Another strength is the relatively large sample size and diverse data, which included pre-schools situated in different parts of the country in both urban and rural municipalities. In addition, precise recipes and information on the foodstuffs used were received from most of the catering services, which adds to the accuracy of the dietary intake data. Moreover, the response rate of the early educators was high $(78 \%)$. By contrast, a limitation was that, in some cases, the food records of several children were completed on the same day, which might have been unduly burdensome for the early educators and might have affected the accuracy of the entries. On the other hand, the use of 
the Children's Food Picture Book, which contained information on children's portion sizes, eased portion size estimation. In the preliminary analyses of the validation study on the Children's Food Picture Book, parents and early educators evaluated portions sizes with rather similar accuracy $^{(36)}$. Compared with previous validation studies, the Children's Food Picture Book developed in the DAGIS study thus seems to perform well. A further possible limitation was that the early educators reported both their practices and opinions and the children's food intake, which might have caused a reporting bias. Nevertheless, the risk of such a bias was mitigated by using the means of all the early educators' responses in the same group for each practice and opinion. This was a particular strength of the present study, as previous research has tended to rely on the responses of just one early educator per group.

\section{Conclusion}

Our results, which in some respects contradicted previous findings, demonstrated that some of the feeding practices and opinions of the early educators were related to healthier dietary intake (higher consumption of vegetables and intake of fibre) among the children, with the strongest associations appearing between dietary intake and staff opinion on the food and on the adequacy of vegetables. However, these are probably both indicators of the quality of food and the availability of vegetables in pre-school, factors which early educators have little possibility to influence. Overall, the present study nevertheless shows that alongside the availability of certain food, early educators' feeding practices and opinions do contribute to children's dietary intake and thus should be taken into account when promoting healthy food intake among preschool children.

\section{Acknowledgements}

Acknowledgements: The authors thank all pre-school managers, staff and families for participating in the DAGIS study. They also thank all research personnel for collecting the data. Financial support: This work was financially supported by Folkhälsan Research Center; University of Helsinki; University of Helsinki future fund (R.L.); the Ministry of Social Affairs and Health; and the Academy of Finland (grant numbers 285439, 287288 and 288038). None of the funders had any role in the design, analysis or writing of this article. Conflict of interest: None. Authorship: R.L. formulated the research question, took part in collecting the data, analysed the data and wrote the article. H.V. and L.K. took part in writing the article. S.M., E.S. and K.N. took part in carrying out the study and writing the article. E.R. designed the study and took part in writing the article. C.R. and M.E. took part in formulating the research question, designing the study and writing the article. Ethics of human subject participation: This study was conducted according to the guidelines laid down in the Declaration of Helsinki and all procedures involving human subjects were approved by the University of Helsinki Ethical Review Board in the Humanities and Social and Behavioural Sciences. Written informed consent was obtained from all subjects. Parents gave consent for their child.

\section{References}

1. Khalsa AS, Kharofa R, Ollberding NJ et al. (2017) Attainment of '5-2-1-0' obesity recommendations in preschool-aged children. Prev Med Rep 8, 79-87.

2. Erkkola M, Kronberg-Kippilä C, Kyttälä P et al. (2009) Sucrose in the diet of 3-year-old Finnish children: sources, determinants and impact on food and nutrient intake. $\mathrm{BrJ}$ Nutr 101, 1209-1217.

3. Afeiche MC, Koyratty BNS, Wang D et al. (2018) Intakes and sources of total and added sugars among 4 to 13-year-old children in China, Mexico and the United States. Pediatr Obes 13, 204-212.

4. Nordic Council of Ministers (2014) Nutrition Recommendations 2012. Copenhagen: Nordic Council of Ministers.

5. World Health Organization (2016) Childhood overweight and obesity. http://www.who.int/dietphysicalactivity/child hood/en/ (accessed May 2018).

6. Craigie AM, Lake AA, Kelly SA et al. (2011) Tracking of obesity-related behaviours from childhood to adulthood: a systematic review. Maturitas 70, 266-284.

7. Mikkilä V, Räsänen L, Raitakari OT et al. (2005) Consistent dietary patterns identified from childhood to adulthood: the Cardiovascular Risk in Young Finns Study. Br J Nutr 93, 923-931.

8. Vereecken C, Rovner A \& Maes L (2010) Associations of parenting styles, parental feeding practices and child characteristics with young children's fruit and vegetable consumption. Appetite 55, 589-596.

9. Park S, Li R \& Birch L (2015) Mothers' child-feeding practices are associated with children's sugar-sweetened beverage intake. J Nutr 145, 806-812.

10. Papaioannou MA, Cross MB, Power TG et al. (2013) Feeding style differences in food parenting practices associated with fruit and vegetable intake in children from low-income families. J Nutr Educ Behav 45, 643-651.

11. Bandura A (1986) Social Foundations of Thought and Action: A Social Cognitive Theory. Englewood Cliffs, NJ: Prentice-Hall.

12. Organisation for Economic Co-operation and Development, Social Policy Division, Directorate of Employment, Labour and Social Affairs (2016) OECD Family Database, PF3.2: Enrolment in childcare and pre-school. http://www. oecd.org/els/soc/PF3_2_Enrolment_childcare_preschool.pdf (accessed April 2018).

13. Larson N, Ward DS, Neelon SB et al. (2011) What role can child-care settings play in obesity prevention? A review of the evidence and call for research efforts. J Am Diet Assoc 111, 1343-1362.

14. Ray C, Määttä S, Lehto R et al. (2016) Influencing factors of children's fruit, vegetable and sugar-enriched food intake in a Finnish preschool setting - preschool personnel's perceptions. Appetite 103, 72-79.

15. Valtion ravitsemusneuvottelukunta (2018) Terveyttä ja iloa ruoasta - varbaiskasvatuksen ruokailusuositus (Health and Joy from Food - Food Recommendations for Early 
Childhood Education and Care). Helsinki: National Institute for Health and Welfare.

16. Terveyden ja hyvinvoinnin laitos, Valtion ravitsemusneuvottelukunta (2016) Syödään yhdessä - ruokasuositukset lapsiperheille (Eating Together - Food Recommendations for Families with Children). Tampere: National Institute for Health and Welfare.

17. Lehtisalo J, Erkkola M, Tapanainen H et al. (2010) Food consumption and nutrient intake in day care and at home in 3-year-old Finnish children. Public Health Nutr 13, 957-964.

18. Kyttälä P, Erkkola M, Lehtinen-Jacks S et al. (2014) Finnish Children Healthy Eating Index (FCHEI) and its associations with family and child characteristics in pre-school children. Public Health Nutr 17, 2519-2527.

19. Gubbels JS, Kremers SP, Stafleu A et al. (2010) Child-care environment and dietary intake of 2- and 3-year-old children. J Hum Nutr Diet 23, 97-101.

20. Gubbels JS, Gerards SM \& Kremers SP (2015) Use of food practices by childcare staff and the association with dietary intake of children at childcare. Nutrients 7, 2161-2175.

21. Andreyeva T, Kenney EL, O'Connell M et al. (2018) Predictors of nutrition quality in early child education settings in Connecticut. J Nutr Educ Behav 50, 458-467.

22. Kharofa RY, Kalkwarf HJ, Khoury JC et al. (2016) Are mealtime best practice guidelines for child care centers associated with energy, vegetable, and fruit intake? Child Obes 12, 52-58.

23. Ward S, Blanger M, Donovan D et al. (2017) Association between childcare educators' practices and preschoolers' physical activity and dietary intake: a cross-sectional analysis. BMJ Open 7, e013657.

24. Määttä S, Lehto R, Nislin M et al. (2015) Increased health and well-being in preschools (DAGIS): rationale and design for a randomized controlled trial. BMC Public Health 15, 402.

25. Lehto E, Ray C, Lehto R et al. (2018) Increased Health and Wellbeing in Preschools (DAGIS) Study - differences in children's energy balance-related behaviors (EBRBs) and in long-term stress by parental educational level. Int J Environ Res Public Health 15, 2313.
26. Benjamin SE, Neelon B, Ball SC et al. (2007) Reliability and validity of a nutrition and physical activity environmental self-assessment for child care. Int J Behav Nutr Phys Act $\mathbf{4}$, 29.

27. Ward D, Hales D, Haverly K et al. (2008) An instrument to assess the obesogenic environment of child care centers. Am J Health Behav 32, 380-386.

28. Nissinen K, Sillanpää H, Korkalo L et al. (2015) Annoskuvakirja lasten ruokamäärien arvioinnin avuksi (The Children's Food Picture Book). Helsinki: Helsingin yliopisto, Seinäjoen ammattikorkeakoulu, Samfundet Folkhälsan.

29. Terveyden ja hyvinvoinnin laitos (2018) Fineli. www.fineli.fi (accessed May 2018).

30. Muthén LK \& Muthén BO (1998-2012) Mplus User's Guide. Los Angeles, CA: Muthén \& Muthén.

31. Mennella JA, Finkbeiner S, Lipchock SV et al. (2014) Preferences for salty and sweet tastes are elevated and related to each other during childhood. PLoS One 9, e92201.

32. American Academy of Pediatrics, American Public Health Association \& National Resource Center for Health and Safety in Child Care (2011) Caring for Our Children: National Health and Safety Performance Standards: Guidelines for Early Care and Education Programs. Washington, DC: American Academy of Pediatrics.

33. Benjamin Neelon SE, Briley ME \& American Dietetic Association (2011) Position of the American Dietetic Association: benchmarks for nutrition in child care. J Am Diet Assoc 111, 607-615.

34. Erinosho TO, Ball SC, Hanson PP et al. (2013) Assessing foods offered to children at child-care centers using the Healthy Eating Index-2005. J Acad Nutr Diet 113, 1084-1089.

35. Ball SC, Benjamin SE \& Ward DS (2008) Dietary intakes in North Carolina child-care centers: are children meeting current recommendations? J Am Diet Assoc 108, 718-721.

36. Nissinen K, Korkalo L, Vepsäläinen H et al. (2018) Accuracy in the estimation of children's food portion sizes against the food picture book: do parents and early educators estimate portions with similar accuracy? J Nutr Sci 7, e35. 